Policy aspirations

As host to the Rio+20 United Nations Conference on Sustainable Development, Brazil will draw international attention to its policy on climate change. In a Commentary, Eduardo Fernandez Silva discusses the policy measures announced by Brazil so far and suggests that they are not yet consistent with the country's emission-reduction goals.

[Commentary p379]

\section{Clean energy?}

Hydroelectric power is one of the renewable energies that, it is hoped, will wean us off our hydrocarbon dependence; unfortunately reality is rarely quite so simple. In a Commentary, Philip Fearnside and Slavador Pueyo argue that methane emissions from tropical hydropower schemes are often underestimated. They reason that when these emissions are accounted for, hydropower emissions can exceed those of fossil fuels for decades, meaning that it cannot really be classed as clean energy. They further argue that accounting omissions such as this potentially undermine international mitigation efforts.

[Commentary p382]

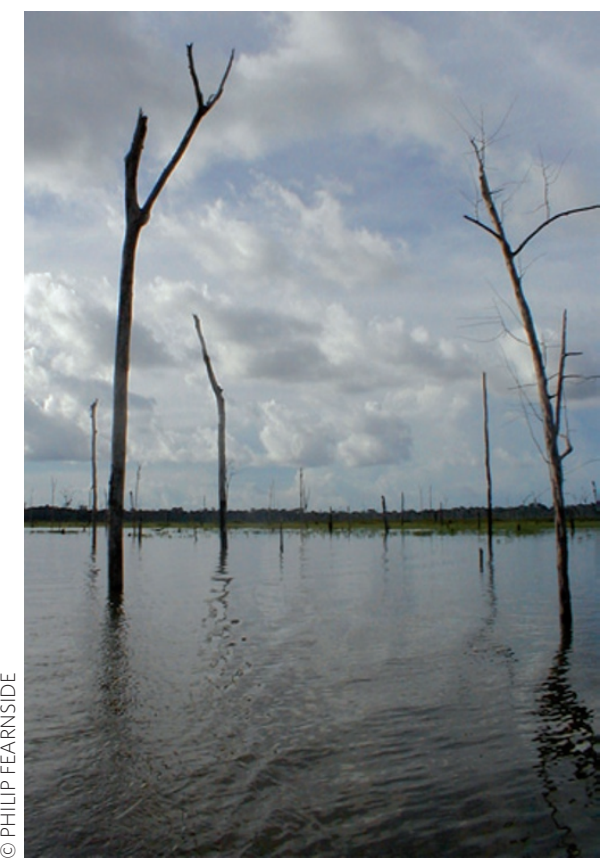

Win-win waste scenarios Industrial symbiosis is the seemingly obvious idea that one company's waste can become another company's raw material, leading to carbon, cost and resource savings. In a News Feature,
Sonja van Renssen reports on examples of industrial symbiosis - early cases of which date back to the 1960s. Some of the drivers and barriers to uptake of this simple but ingenious idea are explored along with the challenges of linking the not always complementary goals of cost and environmental footprint reduction. Like many such initiatives, real environmental gains are possible, but a wholesale solution to the ills of industrial society is not on the cards.

[News Feature p388]

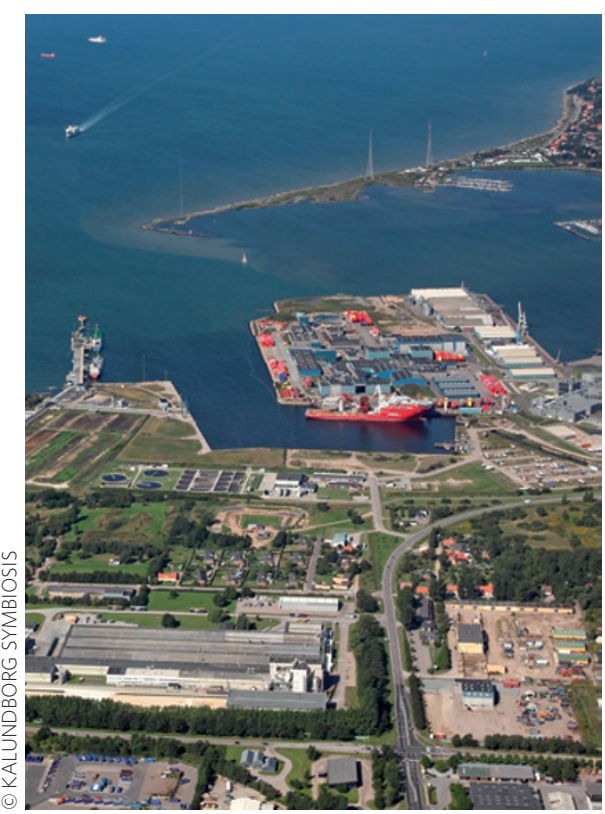

However, its exploitation - a process known as hydraulic fracturing - may also lead to undesired environmental effects that can worsen climate change. In a Commentary, Deyi Hou and coauthors discuss the key issues and some potential solutions.

[Commentary p385]

\section{Arctic vegetative response}

Satellite data suggest that contemporary climate warming has already resulted in increased productivity and shrub biomass over much of the Arctic, but plot-level evidence for vegetation transformation remains sparse. Now research provides plot-scale evidence that links changes in vascular plant abundance to local summer warming in widely dispersed tundra locations across the globe.

[Letter p453]

\section{Emergent migration}

Despite 20 years of concern about human migration in response to environmental pressure, estimates of the numbers likely to move as a result of climate change remain, at best, guesswork. Now computer simulations reveal complex interactions in the way that climate and demographic changes combine to influence migration, suggesting that migration policy interventions will need to be based on both demographics and climate change adaptation to be effective.

[Letter p444; News \& Views p400]

\section{Carbon trading in peril}

The current economic conditions are making Europe's flagship climate policy the Emissions Trading Scheme - hard to implement and maintain. A carbon price of around $€ 7$ per tonne (around five times lower than anticipated) is at the heart of the problem, and policymakers from around the world are watching with interest to see how Europe copes. Sonja van Renssen reports on the challenges up ahead for the Emissions Trading Scheme and market-based carbon solutions more generally.

[Policy Watch p392]

\section{Dangers of extraction}

Natural gas extracted from shale (finegrained laminated rocks) is a relatively clean fossil fuel that is increasingly being used in preference to coal and oil. It has been advocated as a carbon bridge for the next few decades while society works towards a more sustainable energy future.

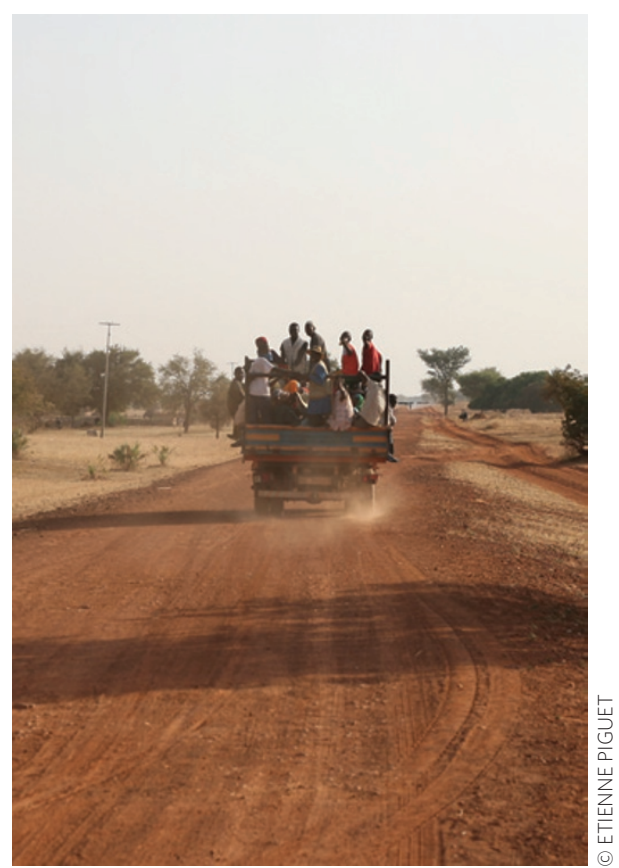

